\title{
Marking Identity through Language in Social Media Discourse by Chuka University Students
}

\author{
Miriti Gervasio*, Dr. Mary Karuri \\ Chuka University, P.o Box 109 60400, Chuka Kenya
}

*Corresponding Author: Miriti Gervasio, Chuka University, P.o Box 109 60400, Chuka Kenya

\begin{abstract}
Interaction via social media has gained popularity owing to the technological advancements that have affected the manner in which people communicate in the contemporary world. This paper is geared towards shedding light on the ways in which language is exploited by the University students to mark their identities through language in their social media discourse. Studies on social media discourse have largely been done in monolingual situations where texts written in one/single language have been analyzed. It was, therefore, necessary to carry out a study in multilingual situation where texts written in English, Kiswahili, Sheng (a Kenyan Pidgin) and local languages are analyzed. The study employed social identity theory in analyzing the data. Descriptive research design and qualitative technique were employed for data analysis. Both snowball and purposive sampling procedures were used. The study reveals that students mark their identities by converging in their messages through the use of special jargon, multimodality, and, simple syntactic structures. It was concluded that the students mark their identities by using language in a similar manner.
\end{abstract}

Keywords: Identity, Social media discourse, Special jargon, Multlingual situations and Multimodality.

Abbreviations: $T$ - text

\section{INTRODUCTION}

As people interact with one another, they mark their identity through language. Identity is typically who an individual is, or the qualities of an individual or group which make them different from others. According to Norton (2013), identity is the way one understands his or her relationship with the world and how that relationship is constructed across space and time. Bucholtz and Hall (2010) simply define identity as the social positioning of the self and the other. Block (2006) notes that it is socially constructed, self-conscious, ongoing narrative as an individual performs, interprets, and projects in dress, bodily movement, actions, and language. Social identity involves participants' roles, positions, relationships, reputations, and other dimensions of social personae, which are conventionally linked to affective and epistemic stances (Ochs\& Capps 1996).

Language and identity are often viewed as dynamic, continuously shifting, and being renegotiated and co-constructed in response to the fluid and ever-changing contexts of our interactions (Coulmas, 2005). Similarly, Darvin (2016) observes that identity is dynamic, multiple, and even contradictory since a person's sense of self and the relation to the world continuously shifts. Hozhabrossadat (2015), shares similar views by noting that linguistic identities are constructed implying that it is not something static but a never-ending process. Language changes our identities and the different forms of language we use shape our identities. This study analysed how the university students mark their identity by using language in social media, and it was discovered that students coin words, use colloquial forms of words, and use a casual style in their discourse.

Speaker's identity is normally displayed by one's linguistic behaviour. A lot of information regarding the speaker or an interactant is revealed through language. Coulmas (2005) posits that language is experienced as a marker of identity given that as people speak, they will reveal who they are, where they grew up, their gender, their station in life, their age and the group they want to belong to. In a university, we have learners who share a lot, and the researcher established their linguistic patterns that defined their identity. The researcher found that students' chats follow a similar pattern that enhances the marking of their identity. 
The context in which language is used determines identity. This is because the way an individual uses language in a certain situation may vary significantly with the way the same person uses language in another context hence different identities. Gee (1999) considers identity as one of the components of the situation. Any situation involves identity as a component. In fact, individuals use different styles or varieties for different purposes. They may use the different varieties of language to recognize and enact different identities in different contexts; they may also use the different varieties to get engaged in all other tasks. One individual might talk, act, and interact in a way that one wants to be recognized as a "street-gang member" in one context and in another context, talk, act and interact in a different way so that one gets recognized as a "gifted student" (Gee, 1999). The university students played different roles, interacted with different kinds of people and therefore depicted a plethora of identities as they chatted and interacted in different ways owing to the variations in the contexts they found themselves in.

Linguistic identities may make individuals be integrated into membership of a community; hence, encourage accommodativeness and solidarity or lead to their being excluded (Hozhabrossadat, 2015). This study focused on how university students tend to include one another (convergence) and how they exclude each other (divergence) in their social media interactions. Inclusion is an indicator of strive to appear similar hence marking of their identity. Interactants have to make choices on whether to use language formally or informally. These choices are mainly determined by the context as well as the relationship that exists among the participants. The communicators may choose the either formal or informal language to index their identity or to seek accommodation by the members of a certain group. Trudgil (1992) explains formality as a word that is used to describe a variety of language which keeps changing depending on the topic/subject or even an activity being undertaken. On the other hand, this study, explored (in) formality as depicted in the social media discourse and how it is used in the marking of identities. The students' social media discourse indicates a high level of informality. The use of informal language demonstrates the close and cordial relations among the students.

Technology has had an impact in transforming the world in multiple, exciting, and unanticipated ways; therefore, facilitating a rapid flow of information capital and services across the globe. The mobile devices, in particular, have dramatically revolutionized the way we work, interact, and communicate with one another in an affordable manner (Gee \&Hayes, 2011). In this world where many people are digitally connected, individuals move in a fluid manner across online and offline spaces making the boundaries of time and space blurred and at the same time transforming nations of private and public domains (Gee \&Hayes, 2011). In real time and space, social media users take pictures and upload them or post status updates making the process a naturalized activity. Using location services, the geographical representation of a person's actual position can be recorded, and this displaces the self and the location so that both are represented in real time, blocking the boundaries between offline and online realities (Kress, 2009). With the increasing use of technology, people have formed various groups that are distinct from others, hence, attracting scholarly works in linguistics on such groups.

This digital revolution has tremendously changed the language triggering an upsurge of new vocabularies, genres, and styles by reshaping writing practices. In the development of a mode of communication whereby writing approximates speaking, instant messaging (IM) and texting facilitate the production of new words and styles that close the gap between speech that is interactive in nature and the capacity of writing which is documental (Warschaver\&Matuchniak, 2010). This study analysed the new words and phrases used by university students in their WhatsApp interaction platform with the aim of determining how such usages enhance the creation of identities by those students.

Generally, when individuals occupy online platforms, they reconstruct language in ways that match the constraints and affordances of various digital spaces. Depending on the communication, if it is either synchronous or asynchronous, the limitations of speed in which text can be delivered and space have led to the evolution and emergency of linguistic structures that conflate the written and the spoken digital media. This has led to easy access and use of multiple modalities. Social media platforms that provide connection of people from all over the globe have provided more opportunities for multilingual encounters and translingual practices, which has revitalized languages and led to the 
assertion of new identities (Darvin, 2016). This study shows how language is used by students to mark their identities.

\section{MeTHOdOLOGY}

This study employed a qualitative research technique and a descriptive research design. It utilized the snowball and purposive sampling procedures. Snowballing was used to identify the WhatsApp groups from which the texts were extracted. Before data collection commenced, the researcher was added to the WhatsApp groups by the various students' group administrators upon request. The study utilized qualitative methods to analyse data. The process began by extracting the texts that demonstrated how students mark their identities in their social media discourse.

\section{Discussions}

Language plays an integral role in establishing how students mark their identities. Identities are constituted in and through language and that; language(s) are used to articulate ideas, to represent social relations and ourselves (Norton, 2013). The Social Identity Theory by Tajfel (1981), used in the analysis of data in this chapter, asserts that individuals adopt group identity and the adoption of the language may be a dialect form, a group slang, and jargon, or a special register. In this paper, an attempt was made to show how multimodality, convergence and divergence, use of special jargon and colloquial variants, and the syntactic structure of the sentences are used to enhance the marking of identities in social media discourse by Chuka University students. It is imperative to observe that Social Identity Theory (SIT) borrows heavily from Speech Accommodation Theory (SAT) which has convergence and divergence as one of its tenets and this study has utilized it in the analysis of the data.

\subsection{Convergence}

This study found that convergence is realized through students' resemblance in their language usage in social media. Students used special jargon mostly known to them. Secondly, the syntactic simplicity of their sentences makes the students appear similar to one another. Thirdly, the students' ability to use more than one linguistic code; English, Kiswahili, the Kenyan pidgin (Sheng) and local languages, enable them to converge easily. Fourthly, students are able to combine a number of features such as pictures, emoticons, and various languages to communicate a unified message. Finally, convergence is made easy by the high level of informality and orality as indicated by the nature of words and the sentences they use.This view is supported by Giles et al. (1991) who posit that mutual convergence can enhance communication innovations at the grammatical, lexical, nonverbal and the prosodic levels which may serve to foster shared family and couple identities as well as emerging small-group identities. Similarly, this kind of observation is supported by Scissors et al. (2009) who argue that linguistic similarity can occur at three levels: the structural level measured in terms of verb tense used, content level or emotion and task related content and the stylistic level indicated by using the same jargon.

\subsubsection{Convergence with the use of Common Languages}

Although these students come from different ethnic backgrounds, many are times they strive to accommodate one another by using linguistic codes that are familiar to each one of them. The three linguistic codes (English, Kiswahili, and Sheng) are exploited in a unique manner, thus demonstrating the identity of the users. Consider the following examples.

\section{T1}

A: I hope lecture ya saa tatu nikama kawa haiko

(I hope the nine o'clock lecture will fail as usual)

B: $U$ always make my nyt 2000

(You always make my night.)

C: Yea haiko

(Yes, it is not there)

D: प्र०० 


\section{(Smiling emoticon)}

In the above conversation, the students converge by using languages that are familiar to each one of them, as well as word forms unique to them such as nyt (night) "kawa" which is a short form of "kawaida" (normally). The students are also converging withthe use of emoticons as in the above example; interactant D uses a smiling emoticon to show his/her pleasure because of a bounced lecture. The use of emoticons is considered as one of the paralinguistic features in social media discourse. Although social media discourse exploits written form of communication, linguistic features used in convergence communication bear a lot of similarity with those of spoken media. This underscores the main argument in the Social Identity Theory that use of a similar register enhances marking of identity.

\subsubsection{Use Paralinguistic Features}

Paralinguistic features in the social media context are depicted through the use of exaggerated spelling, punctuation marks, and use of emoticons, as shown in T2 below.

\section{T2}

A: Sshiit...!!! What the hell is this???

(Crap ...!!! What kind of situation is this???)

B: Exactly what you can see

(Exactly what you can see)

In the above example, the student had posted offensive pictures of Chelsea players (in pampers) and the text shows the reaction of the usage of such words like 'sshiit' and 'hell'.There is the use of exaggerated question marks and spelling by student A. This emphasizes the annoyance because of sending offensive pictures that is socially unacceptable. The use of the words 'shit' and 'hell' is a manifestation of how students use colloquial forms in their conversation. The use of colloquial forms is the next item to be discussed.

\subsubsection{Use of Slang, Colloquial Variants and Kenyan Pidgin "Sheng"}

University students index their identity in the way they use colloquial forms, slang and the Kenyan pidgin commonly known as Sheng. They also use short forms of words, symbols, use of code mixing and switching. The use of similar register and special jargon underscores the importance of Social Identity Theory (SIT) that is used analysis of data in this study. Consider the following examples.

T3

A. Mm nitamkol

(I will call him/her)

B. Wangapi wakona supu

(How many have supplementary exams?)

C. Ww hauko kwa iyo list......ha haha

(You are not in the list ... hahaha)

D. Sasa unacheka nn........wachanga wana

(Why are you laughing.... Stop being immature)

E. Shida nini na yy?

(What's wrong with him?)

F. Qwan umeleft grp?

(Have you left the group?)

G. Yeap....nimeona am alone here

(Yes ...I have seen Iam alone here.)

A: Kuna daro........... qwanihautakam?

(There is a lecture ...will you come?)

B: Nakam ASAP

(Am coming as soon as possible)

$\mathrm{A}_{2} C U$ there 
(See you there)

T4

A. 4n yangu iliget lost banah

(My phone got lost bwana)

B. Sorry brazah

(I'm sorry brother.)

C. Niko na beef na ww

(I have an issue with you)

D. Mbona

(Why?)

E: Ukunitumia notes za class ya mao

(You didn't send maths notes)

D: Nitakusend them 2 day........relax

(I'll send them today... relax)

$A^{l}$ : Waah!!! Kwanit unado unit moja wk mzima

(Waah!!! Are we doing the same unit the whole week?)

B: Qwani unataka kudo ngapi?

(How many do you want to do?)

$A^{2}$ : Nkt!!! u don't need $2 b$ rude kijana

(Nkt!!! you don't need to be rude young man.)

C: Ghaaai!!! Mwathani....... watu waache kuwa rude

(O my God.... people should stop being rude.)

D: Wacheni pressure nyinyi...........

(Can you minimize stress?)

F: zii...... wasee wengine lazima waach eufala kwa grp...... ama waleft

(No.... Some people should either stop their foolishness or leave the group)

G: Plz note that hakuna daro 2 morrow

(Please note there will be no lecture tomorrow)

Form the above examples; it is evident that there is a lot of informality as demonstrated by the kind of lexical items used. The words used in their discourse can easily make one identify with them because one will seldom find these kinds of words in formal situations. There is the use of slang; for instance, the word 'beef' which means bull's meat implies that one is not pleased with the other in social media discourse. Use of words from Sheng is a very common phenomenon in the students discourse as seen in the words 'brazah' for brother, 'supu' for supplementary examinations, 'wasee' for 'wazee' which is used by students to refer to one another. 'Zii' means no, daro means class and 'mao' means mathematics. The use of these words is common among the youth as they speak to one another, but one would least expect them in written language. The use of group identity markers, slang, and colloquial forms is one of the main ways of showing identity as posited in the Social Identity Theory that this study makes use of. Table 1 below provides more examples of Sheng words commonly used by university students. These words are incorporated in their discourse together with other words from English and Kiswahili to convey a unified message, as shown in the above examples in T3 and T4. 
The following table shows some of the Sheng words mostly used by students in their social media discourse

Table1: Sheng words and their meaning

\begin{tabular}{|l|l|}
\hline \multicolumn{1}{|c|}{ Word } & \\
\hline Randa & Plan \\
\hline Bisna & Business \\
\hline Lapi & Laptop \\
\hline Omoka & Go \\
\hline Brazah & Brother \\
\hline Bundaa/ msai & Parent \\
\hline Pack & reside/live \\
\hline Chapaa / ndoo & Money \\
\hline Kuvaana & Fighting \\
\hline Ndai & Car \\
\hline Duda & Partying in a club/ falling down \\
\hline Modi & Teacher \\
\hline Ocha/shag & Upcountry \\
\hline Wasee & $\begin{array}{l}\text { Refers to the students. It is normally borrowed from } \\
\text { the word mzee (man) and then adapted by students to } \\
\text { mean a fellow student in the social media context }\end{array}$ \\
\hline Zii & No \\
\hline Msai & $\begin{array}{l}\text { Refers to a parent but in the text above, itrefers to a } \\
\text { student }\end{array}$ \\
\hline Ghaai!!! & An exclamation that connotes God. \\
\hline Keja & House \\
\hline Mwathani!!! & $\begin{array}{l}\text { An exclamation. The word Mwathani, however, refers } \\
\text { to God. }\end{array}$ \\
\hline Chop & Study \\
\hline Daro & Class \\
\hline Ngori & Danger \\
\hline Mburungo & Cargo \\
\hline Tei & Alcohol \\
\hline Sota & to be broke \\
\hline Mangware & early in the morning \\
\hline
\end{tabular}

Apart from using sheng, students have the ability to code mix English and Kiswahili and come up with new words that communicate their message. From the examples given above in T3 and T4, there is the use of words like "nitamkol," "nitakam," "nimeleft," "nikusend," "iliget" and several others. Table 2 shows how English and Kiswahili morphemes combine to make a single word, which at times comprise a complete sentence with subject, verb, and object (SVO) and at other times, it entails a subject and the verb (SV) when translated into English. In the same word, the tense is also marked. It is also evident that the rules of syntax are adhered to because, in a single word, which is a blend of both English and Kiswahili morphemes, we may have the subject and the verb (SV) or subject, verb and the object (SVO), where number and tense are correctly marked.

Table2: Code Mixing Analysis

\begin{tabular}{|l|l|l|l|l|l|}
\hline \multicolumn{1}{|c|}{ Form } & \multicolumn{1}{c|}{ Subject } & \multicolumn{1}{c|}{ tense } & \multicolumn{1}{c|}{ Object } & \multicolumn{1}{c|}{ Verb } & \multicolumn{1}{c|}{ Gloss } \\
\hline nitamkol & $\mathrm{Ni}(\mathrm{I})$ & $\mathrm{Ta}($ will) future & $\mathrm{M}(\mathrm{him} / \mathrm{her})$ & Kol(call) & I will call him/her \\
\hline Umeleft & $\mathrm{U}(\mathrm{you})$ & $\mathrm{me}($ have) present & & Left & You have left \\
\hline nitakusend & $\mathrm{Ni}(\mathrm{I})$ & $\mathrm{ta}($ will) future & $\mathrm{Ku}(\mathrm{you})$ & Send & I will send you \\
\hline Nakam & $\mathrm{N}$ & a-ing-progressive aspect & & Kam(come) & \\
\hline Iliget & $\mathrm{I}$ (it) & li (past tense) morpheme & & Get & It got \\
\hline Tunado & $\mathrm{Tu}(\mathrm{we})$ & $\begin{array}{l}\text { na(are) present, and } \\
\text { ing(progressive aspect) }\end{array}$ & & Do & We are doing \\
\hline
\end{tabular}

Source: Author 2019

From the above table 2, it is evident that students blend English and Kiswahili in a meticulous manner that may not be common among the older generation. Some English morphemes are at time corrupted, 
as in the case of the word "nitamkol." The morpheme 'kol' represents the free morpheme call. The fact that they are able to code mix the two languages is a proof that their knowledge of the two languages is not questionable. No wonder they qualified to join the university.

Another feature that distinguishes university students from other users of language in social media is the way they shorten their lexes, use of a letter to stand for a word or a combination of letters to form a word (acronym). From T3 and T4 forms such as ' $4 n$ 'for Phone, ' $n n$ ' for nini (what is it), ' $u$ ' for you, 'cu' for see you, 'pliz' for please, 'quiz' for the question and ' $2 b$ 'for to be are good examples. In other contexts, in students' social media discourse, you will definitely find out that their numerous abbreviations and acronyms as evident in T3 where such forms are used. Table 3 below provides more examples of abbreviations and acronyms commonly used by students at the university.

Table3: Acronyms and Abbreviations

\begin{tabular}{|l|l|}
\hline \multicolumn{1}{|c|}{ Acronym/abbreviation } & \\
\hline LOL & laugh out loudly \\
\hline OMG & Oh My God \\
\hline TBH & To Be Honest \\
\hline TBT & Throw Back Thursday \\
\hline NASA & National Sex Academy \\
\hline BTS & Both Teams To Score \\
\hline MWK & Mpango wa kando (secret lover) \\
\hline AR & Always Ready \\
\hline LMK & Let Me Know \\
\hline FFU & Fanya Funjo Uone (a threat) \\
\hline NKT & Not kindly taken \\
\hline MYOB & Mind Your Own Business \\
\hline NSFW & Not Safe for Work \\
\hline NBD & No Big Deal \\
\hline GOAT & Greatest of all Times \\
\hline IMO & In my opinion \\
\hline NVM & Never mind \\
\hline TTYI & Talk to you later \\
\hline WYD & What are doing \\
\hline FOMO & Fear of missing out \\
\hline JK & Just Kidding \\
\hline KK & Cool Okay \\
\hline ASAP & As soon As Possible \\
\hline FYI & For your information \\
\hline
\end{tabular}

Source: 2019

These kinds of linguistic forms are commonly and extensively used by the university students to index their identity and rarely are you likely to encounter them being used by the older generation. The use of such forms as 'prac' for practical, 'lec' for lecturer, 'rep' for representative and 'grp' for group indexes their identity as they revolve around their core business (academics) at the university.

\subsubsection{Social Media Sentences and Marking of Identity}

The university social media discourse is characterized by a kind of sentences that bear a lot of resemblance with those used in the spoken discourse. Most of the sentences used by students in their social media discourse may comprise a single word, a question, or response. A response or a comment may be an emoji, and the students are able to work out the meaning. Another salient feature is the use of simple sentences in both structure and meaning. This implies that they are syntactically and semantically simple in most of the instances. The grammaticality of their sentences is sometimes wanting.

A: Niko na quiz .... Kwani leo hatuta-atend iyo lecture ingine?

(I have a question.... are we not attending the next lecture?) 


$$
\begin{aligned}
& \text { B: Pliz note this....... hakuna daro 2morrow.... lec alisema hatamake } \\
& \text { (Please note........ there is no class tomorrow... the lecturer said he will } \\
& \text { not be available.) }
\end{aligned}
$$

The above example (T5) shows sentences that are simple both syntactically and semantically, but code mixing and switching are used to blend the sentences making them appear unique hence identifying with its users; university students. As indicated by the examples used in this study, students' sentences are also characterized by the use of ellipsis, which is either manifested through exaggerated dots or commas. Under normal circumstances, the ellipsis is indicated by use of three dots and commas are not used. As evident in T6, students often make use of incomplete sentences and their response to a question corresponds to what would be witnessed when people are speaking one on one.

\section{T6}

\section{A: Good evening there is a high probability kutakuwana prac 9:00}

(Good evening, there is a high probability that there will be a practical at 9:00)

\section{$\mathrm{B}: \quad A k i \oplus \odot \odot \odot \odot$}

(True (frowning face)

\section{C: Practical iko confirmed}

(Practical has been confirmed?)

D: Sasawa.

(Alright)

\section{E: Kukuaamakutokua}

(Will it be there or not?)

F: Iko

(It is there.)

G: Ety?

(What?)

$\mathrm{C}^{2}$ : Pracya 9:00 iko

(The practical will be at 9:00)

$\mathrm{B}_{2}$ : Woi

E2: प्र०ण

(Emoji with tears)

$\mathrm{H}$ : fity

(Alright)

In the above example, we have sentences that comprise a single word or an emoticon, just like what happens in the spoken discourse. Emoticons express the paralinguistic features of the language. This may not be a common phenomenon in other types of writing. In T6, students express different feelings when they realize that there would be a practical class the following day in the morning. In the above example, student $\mathrm{B}$ uses the word aki (sure) and an emoticon while $\mathrm{F}$ also uses a single word in his response, "iko" (it is there) and D "sasawa" instead of "sawa" (okay).

The lacking aspect of their grammar is evident in the fact that interact $\mathrm{E}$ is asking whether it would be there or not after his counterpart $\mathrm{C}$ has already indicated there would be apractical class. The sentence is ambiguous. It is also evident from the students' conversation in social media that some of the words are not spelt in accordance with the language in use but in a manner that is in congruent with the way students use such words. This is a pointer to their identity. Consider the response G, "Ety" and H, "Fitty" in which "ety" is a Kiswahili word that has been corrupted and means "what' whereas "fitty" is an English word that has been corrupted by adding letters- "ty" to the word 'fit.' In other contexts, 
you will find forms like "Io" -instead of hiyo (that one), "iyo" instead of hiyo (that one), "ii" instead of hii (this one), "te"instead of the, "dat" instead of that and"diz"instead of this. This implies that students have a way of coming up with their own linguistic forms that are unique to them hence depicting their identity.

\subsubsection{Multimodality of Social Media Messages}

This study found out that multimodality is a common phenomenon in the social media discourse of university students. This is due to their abilities to combine varied resources in their interaction. This makes their conversations more informative. For instance, the feelings of the interactants are conveyed by emoticons. Emoticons are, at times, combined with pictures and written messagesto convey a unified message.

Even though the language is the mostly used resource, multimodality recognizes that language is always employed alongside other semiotic resources and makes meaning because of the orchestration of the modalities and resources. This kind of perspective calls for a paradigm shift, from the most common view that is logo centric, to one that is multimodal in nature. Language needs to be viewed as part of complex sets of interconnectivity forms of human semiosis and not as an independent entity (Christie, 2002). This kind of perception is made a reality in the social media discourse by the university students where they make use of different forms of emotions, as well as different languages in their conversation. Consider the following example.

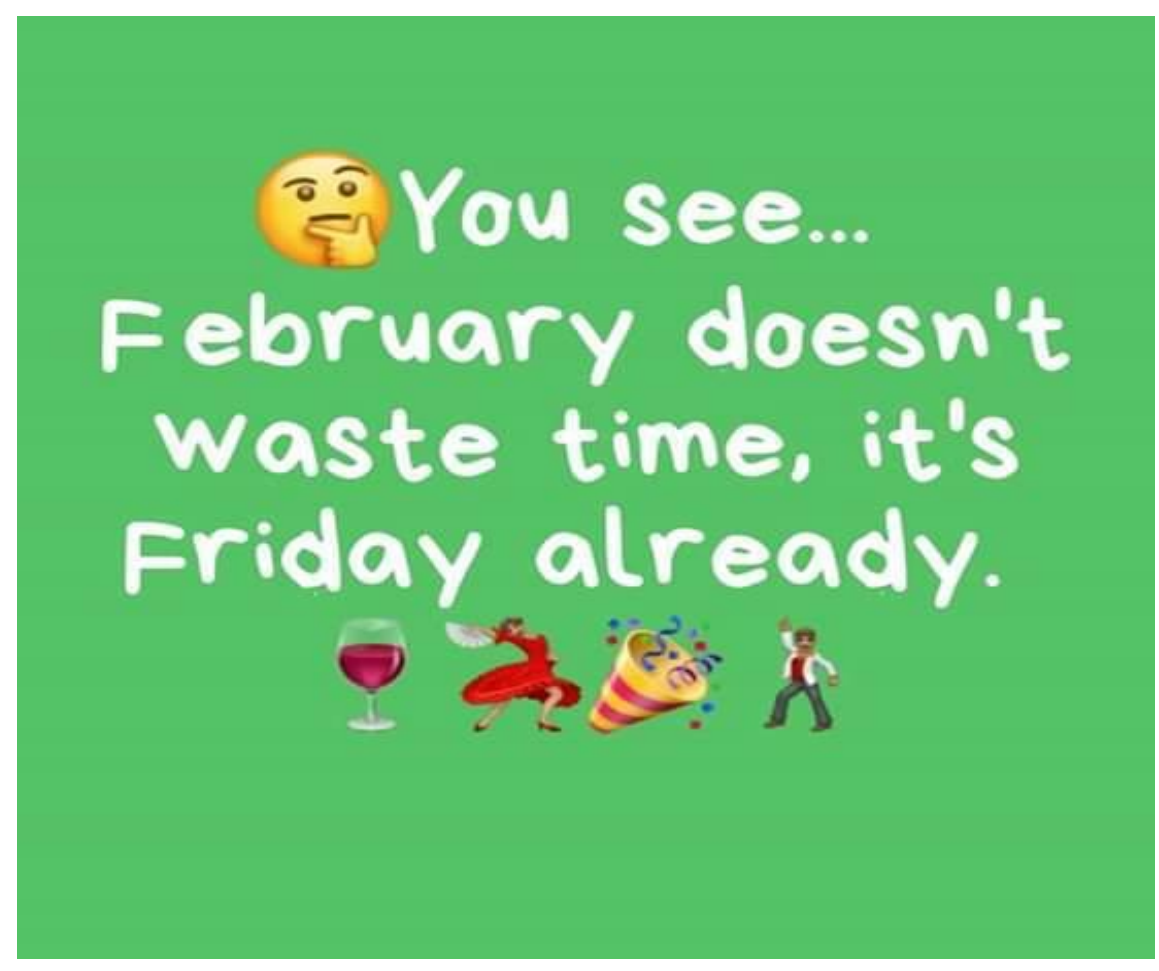

Figure1: Multimodality of Social Media Messages

The above communication demonstrates the multimodality of social media discourse. It can combine two or more media in the process of communication. For instance, drawing from the above example, it is explicit that the first emoticon on top is a facial expression indicating the emotion of surprise because of the days that have elapsed so fast. The facial expression is reinforced by the written message and then the emoticons at the bottom that sets in the partying mood as indicated by a glass of wine and then a music sign between a man and a woman dancing. This indicates that it is on Friday, time to drink and dance. People normally wait for Fridays to relax after a long week's work.

\section{Conclusion}

From the findings and discussions in this chapter, it is explicit that university students mark their identities by converging in their conversations. Convergence is realized through multimodality nature of their messages, and their use of peculiar register/ jargon. The findings of this research show that students put away their personal or subgroup identity for the one that is the most powerful meaning 
that they opt to join the mainstream identity so as to form an in-group identity. Since individuals adopt the group identity, the adoption of the language may be in the form of dialect; in group slang and jargons, or special registers. Students converge in their texts for solidarity purposes and end up creating a distinct group identity. The students' style of writing is casual indicating that they have close relationships with one another

\section{REFERENCES}

[1] Block, D. (2006). Identity in applied linguistics, In O, Tope; W. Goodith (eds.) The sociolinguistics of identity. London: Continuum 31-49

[2] Bulcholtz, M. and Hall, K. (2010) locating identity in language. In C.Llmas\& D Watt (eds). Language and identities. (18-28). Edinburgh UK: Edinburgh University press Ltd

[3] Christie, F. (2002).Classroom discourse analysis; a functional perspective. London and New York: Continuum.

[4] Coulmas, F. (2005).The study of speakers choices. Cambridge: Cambridge University Press.

[5] Darvin, R. (2016).Language and identity in the digital age. Retrieved from https://.www.researchgate.net/ publication/303838217.retrieved on25th January 2018.

[6] Gee, L.P. (1999). An introduction to discourse analysis; theory and method. London and Newyork: Routeledge.

[7] Gee, J. P. \&Hayes, E. R. (2011).Language and learning in the digital age. Abingdon: Routledge.

[8] Hozhabrossdat, S. (2015). Linguistic identities. How code switching and/ coderossing help constructing solidarity or otherness in multilingual societies. Inter.J. Eng.Lit. Cult,3 (6), 194-198

[9] Kress, G. (2009).Multimodality: Asocial semiotic approach to contemporary communication. Abingdon: Rutledge.

[10] Norton, B. (2013).Identity and language learning: Extending the conversation. 2nd edn. Bristol: Multilingual.

[11] Ochs, E \& Capps, L. (1996).Narrating the self. Annual Review of Anthropology, 25: 19-43.

[12] Scissors, L. E., Gill, A. J., Geraghty, K. \&Gergle, D. (2009). CMC, we trust The role of similarity. Proceedings of the SIGCHI Conference on Human Factors in Computing Systems (pp. 527-536). New York: ACM Press [on line]. Retrieved from: http://dgergle.soc.northwestern.edu/resources/ScissorsGill GeraghtyGergle_SimilarityTrust_CHI2009.pf

[13] Tajfel, H. (1981).Human groups and social categories. Cambridge: Cambridge University Press

[14] Trudigil, P. (1992). Introducinglanguage and society. London: Penguin.

[15] Warschauer, M.,\&Matuchniak, T. (2010). New technology and digital worlds: analyzing evidence of equity in access, use, and outcomes. Review of Research in Education, 34(1), 179-225.

Citation: Miriti Gervasio, Dr. Mary Karuri. Marking Identity through Language in Social Media Discourse by Chuka University Students. "International Journal on Studies in English Language and Literature (IJSELL), vol 7, no. 8, 2019, pp. 43-52. doi: http://dx.doi.org/10.20431/2347-3134.0708005.

Copyright: () 2019 Authors. This is an open-access article distributed under the terms of the Creative Commons Attribution License, which permits unrestricted use, distribution, and reproduction in any medium, 